ARTICLE

\title{
High performing and stable supported nano-alloys for the catalytic hydrogenation of levulinic acid to $\gamma$-valerolactone
}

\author{
Wenhao Luo ${ }^{1, \star}$, Meenakshisundaram Sankar ${ }^{1, \star}$, Andrew M. Beale $e^{1,2,3}$, Qian He ${ }^{4}$, Christopher J. Kiely ${ }^{4}$,
} Pieter C.A. Bruijnincx ${ }^{1} \&$ Bert M. Weckhuysen ${ }^{1}$

The catalytic hydrogenation of levulinic acid, a key platform molecule in many biorefinery schemes, into $\gamma$-valerolactone is considered as one of the pivotal reactions to convert lignocellulose-based biomass into renewable fuels and chemicals. Here we report on the development of highly active, selective and stable supported metal catalysts for this reaction and on the beneficial effects of metal nano-alloying. Bimetallic random alloys of gold-palladium and ruthenium-palladium supported on titanium dioxide are prepared with a modified metal impregnation method. Gold-palladium/titanium dioxide shows a marked, $\sim 27$-fold increase in activity (that is, turnover frequency of $0.1 \mathrm{~s}^{-1}$ ) compared with its monometallic counterparts. Although ruthenium-palladium/titanium dioxide is not only exceptionally active (that is, turnover frequency of $0.6 \mathrm{~s}^{-1}$ ), it shows excellent, sustained selectivity to $\gamma$-valerolactone (99\%). The dilution and isolation of ruthenium by palladium is thought to be responsible for this superior catalytic performance. Alloying, furthermore, greatly improves the stability of both supported nano-alloy catalysts.

\footnotetext{
${ }^{1}$ Inorganic Chemistry and Catalysis, Debye Institute for Nanomaterials Science, Utrecht University, Universiteitsweg 99, 3584 CG Utrecht, The Netherlands. ${ }^{2}$ UK Catalysis Hub, Research Complex at Harwell, Rutherford Appleton Laboratory, Oxfordshire OX11 OQX, UK. ${ }^{3}$ Department of Chemistry, University College London, 20 Gordon Street, London WC1H OAJ, UK. ${ }^{4}$ Department of Materials Science and Engineering, Lehigh University, 5 East Packer Avenue, Bethlehem, Pennsylvania 18015, USA. * These authors contributed equally to this work. Correspondence and requests for materials should be addressed to P.C.A.B. (email: p.c.a.bruijnincx@uu.nl) or to B.M.W. (email: b.m.weckhuysen@uu.nl).
} 
$\mathrm{V}$ arious biomass feedstocks and many catalytic conversion routes, involving numerous intermediates and end products, are currently being explored for the production of renewable chemicals and fuels in biorefinery-type operations. A small number of compounds have emerged, however, with the potential to play a pivotal role as primary biorefinery building blocks, that is, as so-called renewable platform molecules ${ }^{1}$. Levulinic acid (LA) is one of these promising platform molecules, as it is produced easily and economically from the carbohydrates in lignocellulosic biomass ${ }^{2-4}$. Many value-added products can in turn be obtained from LA, including polymer monomers (for example, succinic and adipic acid), solvents (for example, methyltetrahydrofuran (MTHF) $)^{5}$, plasticizers (for example, 1,4-pentanediol (PD) $)^{5}$, and fuel components and their precursors (for example, butenes ${ }^{6}$, valeric acid esters ${ }^{7}$ and nonanone $\left.{ }^{8}\right)$. Many of these routes actually involve $\gamma$ valerolactone (GVL), a versatile platform molecule in its own right $^{9}$, as intermediate, making the hydrogenation of LA to GVL a reaction of immense importance (Fig. 1) ${ }^{6,7,10}$.

Many metal-based catalysts have been reported for LA hydrogenation and the application of heterogeneous catalysts, which should in principle be most suitable for large-scale GVL manufacturing, in this reaction has been recently reviewed ${ }^{10}$. Supplementary Table 1 provides an overview of some selected catalyst materials, including productivity values and reaction conditions, reported for the LA-to-GVL process. Supported monometallic noble metal catalysts have been studied most and are typically used with molecular hydrogen in the liquid phase at temperatures ranging from 298 to $523 \mathrm{~K}$. Ru-based catalysts generally give the highest GVL productivities, with $\mathrm{Ru} / \mathrm{C}$ being highly active and selective for hydrogenation of LA. While carbon supports are stable under the highly polar and acidic conditions of a LA hydrogenation process, they do not survive the multiple regeneration cycles required for catalyst reactivation by burningoff coke at high temperatures ${ }^{7}$. In this respect, metal oxide supports, such as $\mathrm{TiO}_{2}$, provide a promising alternative on account of their good stability under both reaction and regeneration conditions $s^{7,11,12}$.

Supported bimetallic heterogeneous catalysts have been widely used in many organic transformations, as such combinations of metals in appropriate proportions and nanostructures can often lead to superior catalytic performance ${ }^{13}$. The advantages that bimetallic catalysts might bring have not yet been fully exploited for biomass conversion reactions, however, especially not for the conversion of LA to $\mathrm{GVL}^{10,14}$. Indeed, the few reported examples have actually met with mixed success. Braden et al. ${ }^{15}$ showed that alloying $\mathrm{Ru}$ with $\mathrm{Re}$ improved catalyst stability against traces of sulfuric acid in the LA feed, traces which would rapidly deactivate the monometallic $\mathrm{Ru} / \mathrm{C}$ catalyst. The activity of the bimetallic catalyst was considerably lower than the activity of $\mathrm{Ru} / \mathrm{C}$ in the absence of sulfuric acid, however. Wettstein et al. ${ }^{16}$ reported that alloying $\mathrm{Sn}$ with $\mathrm{Ru} / \mathrm{C}$ led to highly stable and GVL-selective catalysts in the hydrogenation of LA, but again at the expense of activity. In contrast, Lange et al. ${ }^{11}$ concluded that alloying of supported Pt catalysts with Re or Ru did not improve performance, but led to reduced initial activity and enhanced deactivation instead.

Very recently, Yang et al. ${ }^{17}$ reported on the use of $\mathrm{Ru}-\mathrm{Ni}$ bimetallic nanoparticles inside ordered mesoporous carbons; the bimetallic catalyst proved highly stable over multiple reuse cycles displaying an activity that is similar to the corresponding monometallic $\mathrm{Ru}$ catalyst. In another recent report, Shimizu et al. ${ }^{18}$ developed $\mathrm{Ni}-\mathrm{MoO}_{\mathrm{x}}$-based catalysts as a non-noble metalbased alternative to $\mathrm{Ru} / \mathrm{TiO}_{2}$. A beneficial effect of alloying on activity was suggested, but the catalysts were not quite as active as the benchmark Ru-based ones.

As with monometallic catalysts, the performance of supported bimetallic nanoparticles is highly dependent on their compositional and structural characteristics, features that are ultimately determined by the preparation method ${ }^{19}$. Although many synthesis strategies have been reported, precise control over both particle size and the extent of alloy mixing is still a challenge. Recently, one of us reported on an 'excess-anion', modified impregnation methodology $\left(M_{\mathrm{Im}}\right)$ for the synthesis of supported $\mathrm{Au}-\mathrm{Pd}$ catalysts with very narrow particle size distributions and a quite homogeneous, random alloy structure ${ }^{20}$. The $M_{\text {Im }}$ procedure involves the addition of an excess of chloride ions (in the form of dilute $\mathrm{HCl}$ ) in the impregnation solution during the preparation of supported Au-Pd nanoparticles. This excess of chloride ions eliminates one of the major structural problems observed in supported Au-Pd nanoparticles, that is, size-dependent compositional variation. In other words, this excess chloride ions increases the concentration of $\mathrm{Au}$ in the small $\mathrm{Au}-\mathrm{Pd}$ particles at the expense of large micrometre-sized gold-only particles ${ }^{20}$. The $\mathrm{Au}-\mathrm{Pd}$ catalysts were found to be very active in direct hydrogen peroxide synthesis and aerobic alcohol oxidation ${ }^{21}$.

In this work, we demonstrate that the controlled preparation of supported bimetallic nanoparticles via the $M_{\mathrm{Im}}$ synthesis methodology has a marked, positive effect on the catalysts' activity, selectivity and stability in the hydrogenation of LA to GVL. The performance of the bimetallic catalysts $\mathrm{Au}-\mathrm{Pd} / \mathrm{TiO}_{2}$ and $\mathrm{Ru}-\mathrm{Pd} / \mathrm{TiO}_{2}$ (both with equimolar metal ratio) is compared with their monometallic counterparts. Insights into the reasons for the superior catalytic performance of bimetallic systems were provided by a combination of scanning transmission electron microscopy (STEM), X-ray absorption spectroscopy (XAS), X-ray photoelectron spectroscopy (XPS) and Fourier transform infrared spectroscopy (FT-IR) studies using $\mathrm{CO}$ as a probe molecule. On the basis of this detailed characterization, it is found that the beneficial effect of proper $\mathrm{Au}-\mathrm{Pd}$ and $\mathrm{Ru}-\mathrm{Pd}$ nano-alloying is the result of electronic modification of Pd in the former catalyst and dilution and isolation of $\mathrm{Ru}$ in the latter.

\section{Results}

Catalyst performance and stability. Initially, we tested $1 \%$ $\mathrm{Au}-\mathrm{Pd} / \mathrm{TiO}_{2}\left(M_{\mathrm{Im}}\right)$ under batch conditions with a $10 \mathrm{wt} \%$

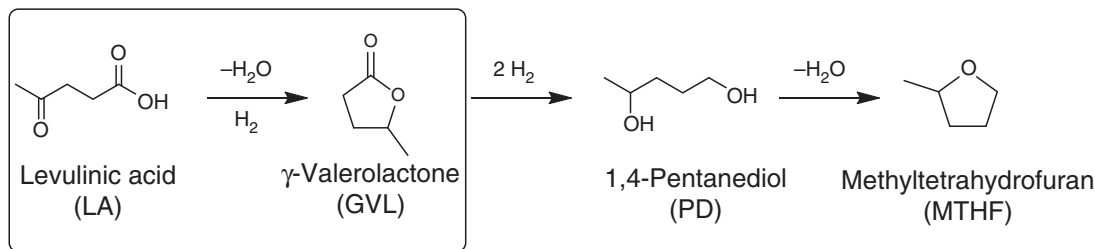

Figure 1 | Catalytic conversion of levulinic acid. Reaction scheme for the catalytic conversion of the platform molecule levulinic acid (LA), which can be easily produced from the carbohydrate fraction in lignocellulosic biomass. Consecutive hydrogenation and dehydration steps can transform LA into the useful chemicals $\gamma$-valerolactone (GVL), 1,4-pentanediol (PD) and methyltetrahydrofuran (MTHF). 
solution of LA in dioxane at $473 \mathrm{~K}$ and 40 bar $\mathrm{H}_{2}$. The corresponding monometallic $1 \% \mathrm{Au} / \mathrm{TiO}_{2}\left(M_{\mathrm{Im}}\right)$ and $1 \% \mathrm{Pd} / \mathrm{TiO}_{2}$ $\left(M_{\mathrm{Im}}\right)$ catalysts were also tested under identical conditions for comparison; all time-on-line yields of GVL (in mol\%) are given in Fig. 2a. Complete LA consumption and product formation profiles are presented in Supplementary Figs 1-3. The monometallic $\mathrm{Au}$ and $\mathrm{Pd}$ catalysts were almost inactive with molar conversions reaching only 3.6 and $2.5 \%$ after $4 \mathrm{~h}$, respectively. Consequently, GVL productivities, as shown in Fig. $2 \mathrm{~b}$, are very low at $0.073 \mathrm{~mol}_{\mathrm{GVL}} \mathrm{g}_{\text {metal }}^{-1} \mathrm{~h}^{-1}$ (Au, TOF $\left.0.004 \mathrm{~s}^{-1}\right)$ and $0.054 \mathrm{~mol}_{\mathrm{GVL}} \mathrm{g}_{\text {metal }}^{-1} \mathrm{~h}^{-1}\left(\mathrm{Pd}\right.$, TOF $\left.0.005 \mathrm{~s}^{-1}\right)$. In strong contrast, the bimetallic Au-Pd catalyst displayed a substantially higher catalytic activity under identical conditions, giving 90\% conversion of LA at $97.5 \%$ GVL selectivity; LA conversion is quantitative after $5 \mathrm{~h}$, with $97.3 \%$ selectivity to GVL. GVL productivity thus improved $\sim 27$-fold to $1.97 \mathrm{~mol}_{\mathrm{GVL}} \mathrm{g}_{\text {metal }}^{-1} \mathrm{~h}^{-1}$ (TOF $0.1 \mathrm{~s}^{-1}$ ). Small amounts of PD (0.4\%) and MTHF (0.3\%) are formed as by-products by consecutive hydrodeoxygenation reactions (Fig. 1). Time-on-line data at different LA concentrations and hydrogen pressures are presented for $1 \% \mathrm{Au}-\mathrm{Pd} / \mathrm{TiO}_{2}\left(\mathrm{M}_{\mathrm{Im}}\right)$ in Supplementary Fig. 4.

Encouraged by this promising result and taking into account that $\mathrm{Ru}$-based catalysts are typically most active in LA hydrogenation, we prepared a bimetallic $1 \% \mathrm{Ru}-\mathrm{Pd} / \mathrm{TiO}_{2}\left(M_{\mathrm{Im}}\right)$ catalyst using the $M_{\mathrm{Im}}$ synthesis method and tested it under our standard reaction conditions. The results, including a comparison with various monometallic $1 \% \mathrm{Ru} / \mathrm{TiO}_{2}$ catalysts, are summarized in Fig. 2c,d, as well as in Supplementary Figs 5-8. With the bimetallic
$1 \% \mathrm{Ru}-\mathrm{Pd} / \mathrm{TiO}_{2}\left(M_{\mathrm{Im}}\right)$ catalyst after $30 \mathrm{~min}$, quantitative conversion of LA ( $>99 \%$ ) was observed with a very high GVL selectivity of $99.6 \%$, corresponding to a productivity of $17.2 \mathrm{~mol}_{\mathrm{GVL}} \mathrm{g}_{\mathrm{metal}}^{-1} \mathrm{~h}^{-1}$ (TOF $0.6 \mathrm{~s}^{-1}$ ). The corresponding monometallic $1 \% \mathrm{Ru} / \mathrm{TiO}_{2}$ $\left(M_{\mathrm{Im}}\right)$ catalyst gave quantitative LA conversion after $40 \mathrm{~min}$ with 99.0\% selectivity to GVL (productivity of $16.4 \mathrm{~mol}_{\mathrm{GVL}} \mathrm{g}_{\text {metal }}^{-1} \mathrm{~h}^{-1}$, TOF $0.5 \mathrm{~s}^{-1}$ ). Notably, GVL selectivity actually decreased to $93.0 \%$ with $1 \% \mathrm{Ru} / \mathrm{TiO}_{2}\left(\mathrm{M}_{\mathrm{Im}}\right)$ at longer reaction times of up to $2 \mathrm{~h}$, with PD (1.2\%) and MTHF (0.7\%) being formed as by-products (Fig. 1). In contrast, with the Ru-Pd catalyst, molar selectivity of GVL remained stable at $\sim 99 \%$ even after $2 \mathrm{~h}$ of reaction. Compared with the marked improvement in catalyst activity seen on alloying $\mathrm{Au}$ with Pd, the improvement in GVL productivity is more limited for $\mathrm{Ru}-\mathrm{Pd}$, but alloying did help in achieving and maintaining a very good GVL selectivity and, as importantly, improved the stability of the catalyst.

The stabilities of the bimetallic $1 \% \mathrm{Ru}-\mathrm{Pd} / \mathrm{TiO}_{2}\left(M_{\mathrm{Im}}\right)$ and $1 \%$ $\mathrm{Au}-\mathrm{Pd} / \mathrm{TiO}_{2}\left(M_{\mathrm{Im}}\right)$ catalysts were examined by performing three consecutive catalytic runs and the recyclability results of the catalysts are shown in Fig. 3. Catalytic activity and selectivity were also compared at different LA conversion levels. All results show that GVL selectivities and yields are sustained on multiple re-use. The limited leaching of the metal phase (Supplementary Table 2) and minimal loss of surface area (Supplementary Table 3 ) further illustrate that both bimetallic catalysts did not show significant deactivation during the three consecutive catalytic runs.

Although the addition of $\mathrm{HCl}$ to the precursor mixture is essential for generating alloys of uniform composition, it is not
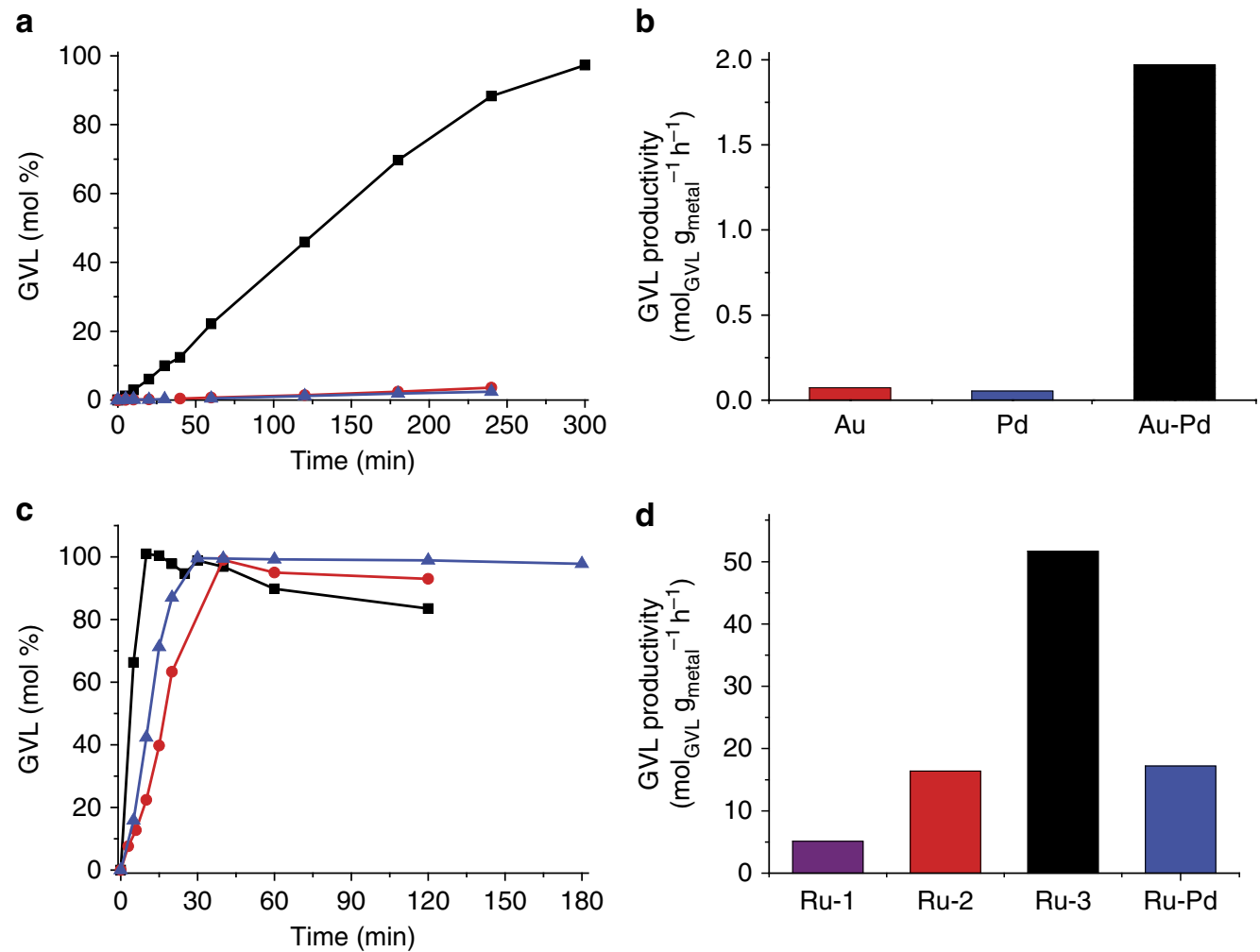

Figure 2 | Catalytic performance of bimetallic and monometallic catalysts. (a) Production of GVL as a function of time during the hydrogenation of $L A$ using monometallic $1 \% \mathrm{Au} / \mathrm{TiO}_{2}\left(\mathrm{M}_{\mathrm{lm}}\right)$ (red circles) and $1 \% \mathrm{Pd} / \mathrm{TiO}_{2}\left(\mathrm{M}_{\mathrm{lm}}\right)$ (blue triangles) and bimetallic $1 \% \mathrm{Au}-\mathrm{Pd} / \mathrm{TiO} \mathrm{O}_{2}\left(\mathrm{M}_{\mathrm{lm}}\right)$ (black squares) catalysts. (b) Comparison of $\mathrm{GVL}$ productivities of $\mathrm{TiO}_{2}$ supported $\mathrm{Au}, \mathrm{Pd}$ and $\mathrm{Au}-\mathrm{Pd}$ catalysts after $4 \mathrm{~h}$ of reaction time. (c) Production of $\mathrm{GVL}$ as a function of time during the hydrogenation of $\mathrm{LA}$ using monometallic $1 \% \mathrm{Ru} / \mathrm{TiO}_{2}\left(\mathrm{M}_{\mathrm{Im}}\right)$ (red circles, $\left.\mathrm{Ru}-2\right), 1 \% \mathrm{Ru} / \mathrm{TiO}_{2}\left(\mathrm{M}_{\mathrm{Im}}, \mathrm{O} \mathrm{M} \mathrm{HCl}\right.$ ) (black squares, Ru-3) and bimetallic $1 \% \mathrm{Ru}-\mathrm{Pd} / \mathrm{TiO}_{2}\left(\mathrm{M}_{\mathrm{Im}}\right)$ (blue triangles, Ru-Pd) catalysts. (d) Comparison of GVL productivities of supported 1\% Ru/TiO $2\left(W_{\mathrm{Im}}\right)(\mathrm{Ru}-1), 1 \% \mathrm{Ru} / \mathrm{TiO} \mathrm{O}_{2}\left(\mathrm{M}_{\mathrm{Im}}\right)$ $(\mathrm{Ru}-2), 1 \% \mathrm{Ru} / \mathrm{TiO}_{2}\left(\mathrm{Mlm}_{\mathrm{Im}} \mathrm{O} \mathrm{M} \mathrm{HCl}\right)(\mathrm{Ru}-3)$ and $1 \% \mathrm{Ru}-\mathrm{Pd} / \mathrm{TiO}_{2}\left(\mathrm{M}_{\mathrm{Im}}\right)(\mathrm{Ru}-\mathrm{Pd})$ after $4 \mathrm{~h}$ of reaction time. Reaction conditions: $T=473 \mathrm{~K} ; p_{\mathrm{H}_{2}}=40$ bar; $10 \mathrm{wt} \% \mathrm{LA}$ in dioxane; LA to Ru weight ratio $=1,000$. 
necessarily required for monometallic catalyst synthesis. We therefore also synthesized a $1 \% \mathrm{Ru} / \mathrm{TiO}_{2}\left(M_{\mathrm{Im}}, 0 \mathrm{M} \mathrm{HCl}\right)$ catalyst without using excess $\mathrm{HCl}$. This catalyst, labelled as $\mathrm{Ru}-3$ in Fig. 2d, showed exceptionally high activity. The GVL productivity of $51.7 \mathrm{~mol}_{\mathrm{GVL}} \mathrm{g}_{\text {metal }}^{-1} \mathrm{~h}^{-1}$ (TOF $2.0 \mathrm{~s}^{-1}$ ) is much higher than the $16.4 \mathrm{~mol}_{\mathrm{GVL}} \mathrm{g}_{\text {metal }}^{-1} \mathrm{~h}^{-1}$ obtained for $1 \% \mathrm{Ru} / \mathrm{TiO}_{2}\left(M_{\mathrm{Im}}\right)$ (TOF $\left.0.5 \mathrm{~s}^{-1}\right)$ prepared with an excess of $0.5 \mathrm{M} \mathrm{HCl}$ and labelled as $\mathrm{Ru}-2$. The highly active $1 \% \mathrm{Ru} / \mathrm{TiO}_{2}\left(M_{\mathrm{Im}}, 0 \mathrm{M} \mathrm{HCl}\right)$ catalyst thus outperforms all catalysts tested by us ${ }^{12}$ and, as far as we are aware, others (Supplementary Table 1$)^{10}$. As for $1 \% \mathrm{Ru} / \mathrm{TiO}_{2}\left(\mathrm{M}_{\mathrm{Im}}\right)$, some sintering of the ruthenium nanoparticles was seen for the spent $1 \%$ $\mathrm{Ru} / \mathrm{TiO}_{2}\left(M_{\mathrm{Im}}, 0 \mathrm{M} \mathrm{HCl}\right)$ catalyst, however. For comparison, we prepared a $1 \% \mathrm{Ru} / \mathrm{TiO}_{2}$ catalyst by conventional wet-impregnation followed by calcination and reduction, as previously reported ${ }^{12}$. The GVL productivity of this catalyst, labelled as $\mathrm{Ru}-1$ and tested under identical reaction conditions, amounted to $5.14 \mathrm{~mol}_{\mathrm{GV}} \mathrm{g}_{\text {metal }}^{-1} \mathrm{~h}^{-1}$ (TOF $0.2 \mathrm{~s}^{-1}$ ), a value more similar to the productivities of those supported $\mathrm{Ru}$ catalysts listed in a recent review article ${ }^{10}$. These results nonetheless demonstrate the importance of system-specific synthesis strategies to achieve exceptionally high catalytic activity.

Metal particle size and alloy formation. The composition and nanostructure of both bimetallic catalysts were studied by aberration-corrected STEM (AC-STEM). The mean size of the supported metal nanoparticles of the $1 \% \mathrm{Au}-\mathrm{Pd} / \mathrm{TiO}_{2}\left(\mathrm{M}_{\mathrm{Im}}\right)$ sample was $1.5 \mathrm{~nm}$ (Fig. 4a,b). X-ray Energy Dispersive Spectroscopy (XEDS) analysis confirmed these nanoparticles to be $\mathrm{Au}-\mathrm{Pd}$ alloys (Fig. 4c,d). Small sub-nm clusters were also apparent in this material (Supplementary Fig. 9a), as were a limited amount of larger $\mathrm{Au}$ particles of about $0.1-0.5 \mu \mathrm{m}$ in size (Supplementary Fig. 10). The mean size of the supported metal particles on $1 \% \mathrm{Ru}-$ $\mathrm{Pd} / \mathrm{TiO}_{2}\left(M_{\mathrm{Im}}\right)$ was slightly smaller at $1.2 \mathrm{~nm}$ (Fig. $\left.4 \mathrm{e}, \mathrm{f}\right)$, with XEDS analysis also confirming them to be Ru-Pd alloys (Fig. 4g-l). Many sub-nm clusters were again apparent (Supplementary Fig. 9b), but SEM analysis did not show any $\mu \mathrm{m}$-scale particles for this sample (Supplementary Fig. 11).

Any changes in the mean metal particle diameters of the fresh and spent catalysts were examined by TEM (Fig. 5). All spent monometallic catalysts show an increase in the metal particle size and broadening of the distribution after the first catalytic run. In contrast, both bimetallic materials showed no or only a marginal increase in particle size, even after three catalytic runs, clearly illustrating the advantageous effect alloying has on stability.

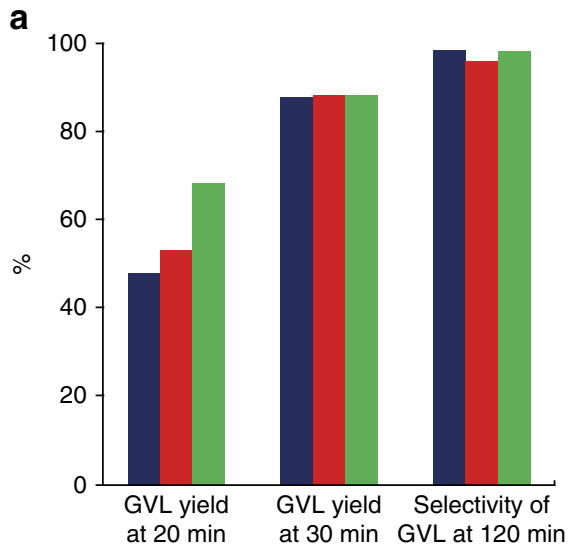

To probe how representative the STEM results are for the entire catalyst samples, the materials were also characterized by extended X-ray absorption fine structure (EXAFS) measurements at the $\mathrm{Au} \mathrm{L}_{3}, \mathrm{Pd} \mathrm{K}$ and $\mathrm{Ru} \mathrm{K}$ edges. The obtained results are summarized in Table 1, while the EXAFS spectra and associated Fourier Transform (FT) data can be found in Supplementary Figs 12,13. The EXAFS data indeed confirm the presence of bimetallic species and the bimetallic coordination numbers are given in Table 1 . For $1 \% \mathrm{Au}-\mathrm{Pd} / \mathrm{TiO}_{2}\left(\mathrm{M}_{\mathrm{Im}}\right)$, the presence of bimetallic species is immediately evident from the FT data at both edges. Two intense peaks in the FTs are observed as a consequence of a ' $\pi$ phase flip' in the backscattering amplitude from $6 \AA^{-1}$ for Au, resulting in a splitting of the major contribution in the FT into a high and low $r$ component ${ }^{22,23}$. This occurs when two elements are present in equivalent amounts; often the splitting and intensity of the low $r$ contribution become more intense with an increasing number of bimetallic bonds. The mismatch in the total coordination number from an analysis of the $\mathrm{Au} \mathrm{L}_{3}$-edge (7.3) and $\mathrm{Pd}$ (3.0) $\mathrm{K}$-edge data is testament to a large number of $\mathrm{Au}-\mathrm{Au}$ contributions due to the additional presence of larger $(\sim \mu \mathrm{m}$ sized) Au-rich particles, as also seen by STEM-XEDS. From a Pd K-edge perspective, the smaller overall coordination number suggests that much of the $\mathrm{Pd}$ is associated with $\mathrm{Au}$. For the $1 \%$ $\mathrm{Ru}-\mathrm{Pd} / \mathrm{TiO}_{2}\left(M_{\mathrm{Im}}\right)$ sample, the similarity in X-ray scattering efficiency precludes distinguishing between the bimetal components. However, instead, a first shell analysis assuming one metal-metal (M-M) scatterer type can be performed on the basis that STEM-XEDS confirms the bimetallic nature of the metal particles for this sample. The closeness in the coordination numbers of both elements from an analysis of both edges supports the notion that the $\mathrm{Pd}$ and $\mathrm{Ru}$ exist within intimately mixed bimetallic particles. The large number of $\mathrm{M}-\mathrm{O}$ bond distances determined and the low $\mathrm{M}-\mathrm{M}$ coordination numbers seen for both edges are also consistent with the STEM analysis in that the particles are very small, smaller than that seen for the Au$\mathrm{Pd}$ sample. In addition, the shorter distances of the $\mathrm{Ru}-\mathrm{O}$ and $\mathrm{Ru}-$ $\mathrm{Ru}$ bonds with $1 \% \mathrm{Ru} / \mathrm{TiO}_{2}\left(\mathrm{M}_{\mathrm{Im}}, 0 \mathrm{M} \mathrm{HCl}\right)$ as compared with $1 \%$ $\mathrm{Ru}-\mathrm{Pd} / \mathrm{TiO}_{2}\left(M_{\mathrm{Im}}\right)$ (Table 1$)$ indicate that even smaller particles are present in the $1 \% \mathrm{Ru} / \mathrm{TiO}_{2}\left(M_{\mathrm{Im}}, 0 \mathrm{M} \mathrm{HCl}\right)$ catalyst, corroborating the TEM results.

All fresh monometallic and bimetallic catalysts were also characterized by XPS. Figure 6 shows the Au 4 f, Ru 3d and Pd 3d XPS spectra of a selection of mono- and bimetallic catalysts, while the Ti $2 \mathrm{p}$ and $\mathrm{O} 1 \mathrm{~s}$ XPS spectra can be found in Supplementary

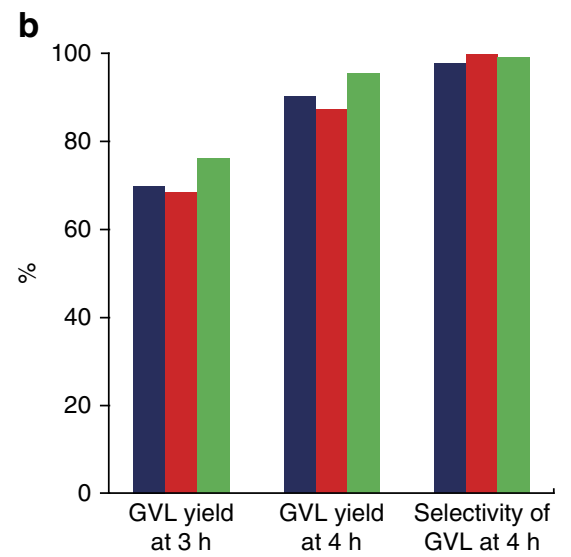

Figure 3 | Recyclability tests of the bimetallic catalysts. Recyclability tests were performed at different $L A$ conversion levels and GVL selectivities. No significant catalyst deactivation was detected after three consecutive catalytic runs. (a) $1 \%$ Ru-Pd/TiO $\left(M_{I m}\right)$. (b) $1 \%$ Au-Pd/TiO $\left(M_{I m}\right)$. The blue, red and green bars represent yields and selectivities obtained in the first, second and third catalytic runs, respectively. 


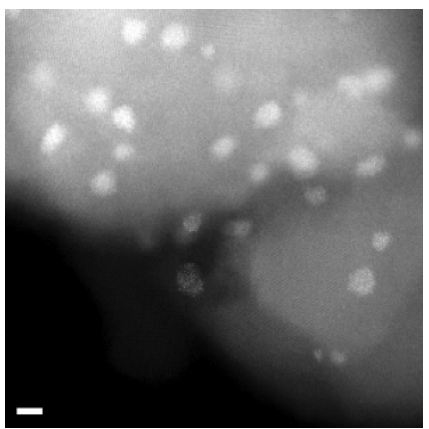

b

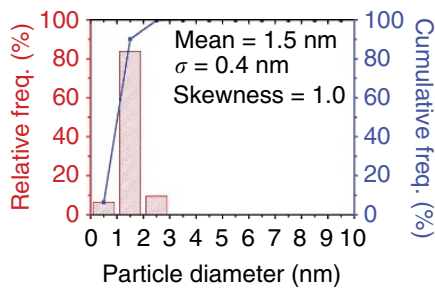

i

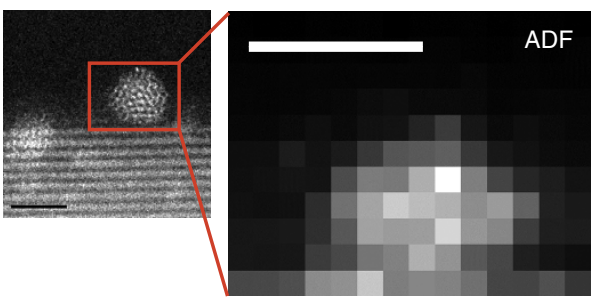

C

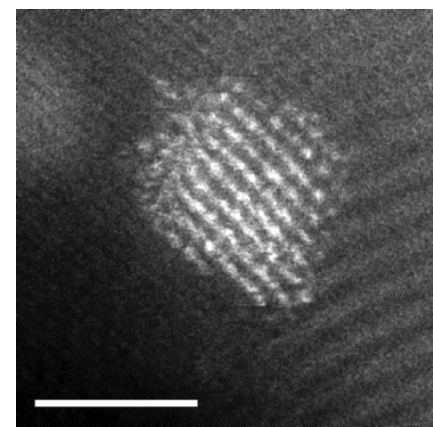

d

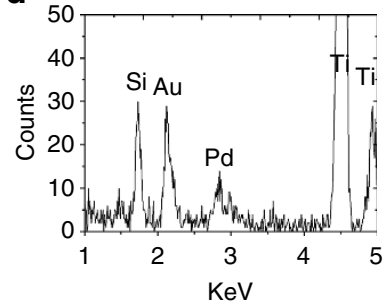

e

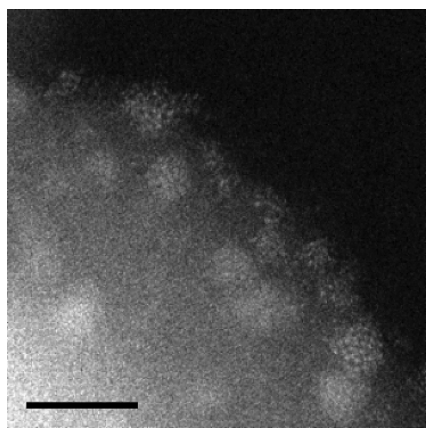

f

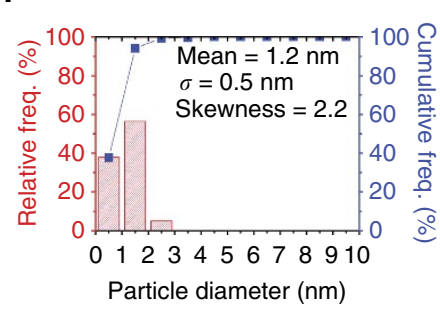

k

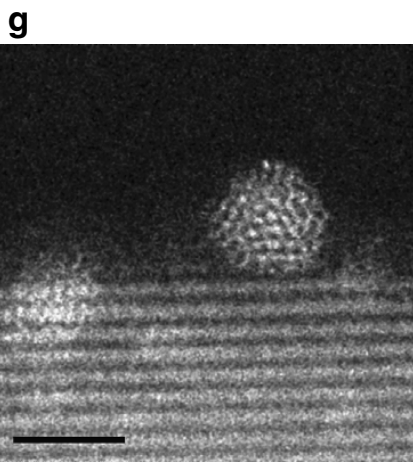

h

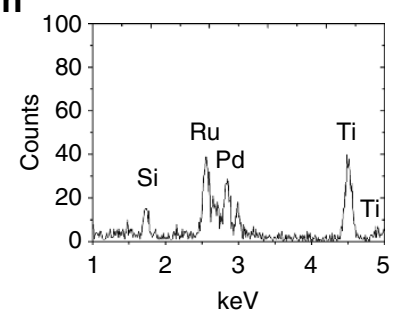

j

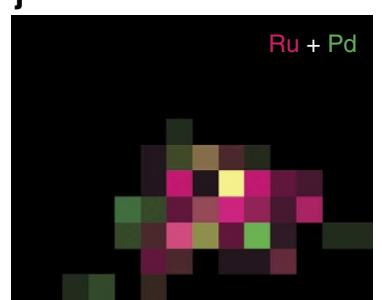

I

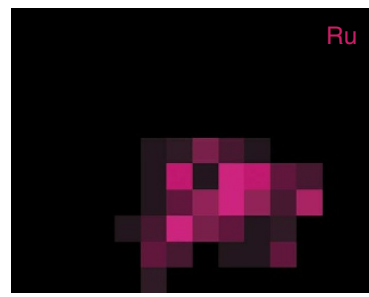

Figure 4 | STEM analysis of the bimetallic catalysts. (a) HAADF image of $1 \% \mathrm{Au}-\mathrm{Pd} / \mathrm{TiO}_{2}\left(M_{\mathrm{Im}}\right)$ showing typical particle sizes. (b) Corresponding particle size distribution derived from measurements of over 500 particles found on $1 \% \mathrm{Au}-\mathrm{Pd} / \mathrm{TiO}_{2}\left(\mathrm{M}_{\mathrm{Im}}\right)$. (c) HAADF image of an individual metal nanoparticle on $1 \% \mathrm{Au}-\mathrm{Pd} / \mathrm{TiO}_{2}\left(\mathrm{M}_{\mathrm{lm}}\right)$. (d) Its corresponding XEDS spectrum confirming it is a Au-Pd alloy. (e) HAADF image of $1 \% \mathrm{Ru}-\mathrm{Pd} / \mathrm{TiO}{ }_{2}\left(M_{\mathrm{lm}}\right)$ showing typical particle sizes. (f) Corresponding particle size distribution derived from measurements of over 500 particles on $1 \% \mathrm{Ru}-\mathrm{Pd} / \mathrm{TiO} \mathrm{I}_{2}\left(\mathrm{M}_{\mathrm{Im}}\right)$. (g) $\mathrm{HAADF}$ image of an individual metal nanoparticle on $1 \% \mathrm{Ru}-\mathrm{Pd} / \mathrm{TiO}_{2}\left(M_{\mathrm{Im}}\right)$. (h) Its corresponding XEDS spectrum confirming it is a Ru-Pd alloy. (i) Zoom-in ADF image of an individual metal nanoparticle on $1 \% \mathrm{Ru}-\mathrm{Pd} / \mathrm{TiO}_{2}\left(M_{\mathrm{lm}}\right)$. (j) Zoom-in elemental map of Ru (pink) and Pd (green). (k) Zoom-in Pd (green) elemental map. (I) Zoom-in Ru (pink) elemental map. The scale bar is $2 \mathrm{~nm}$ in all figures.

Fig. 14. Supplementary Table 4 summarizes the measured XPS binding energies (BE) for the different $M_{\mathrm{Im}}$ catalysts. For $1 \% \mathrm{Au} /$ $\mathrm{TiO}_{2}\left(M_{\mathrm{Im}}\right)$, the Au $4 \mathrm{f}_{7 / 2}$ signal is observed at $84.2 \mathrm{eV}$ (Fig. 6a), which is close to the binding energies previously reported for $\mathrm{Au} /$ $\mathrm{TiO}_{2}$ (refs 24-26) and $\mathrm{Au} / \mathrm{Fe}_{2} \mathrm{O}_{3}$ samples ${ }^{27}$. The same signal showed a small negative shift of $-0.2 \mathrm{eV}$, from 84.2 to $84.0 \mathrm{eV}$ for $1 \% \mathrm{Au}-\mathrm{Pd} / \mathrm{TiO}_{2}\left(\mathrm{M}_{\mathrm{Im}}\right)$. Similar small negative shifts of $-0.25 \mathrm{eV}$ to $-0.56 \mathrm{eV}$ in $\mathrm{Au}_{4 / 2} \mathrm{BE}$ 's have previously been observed for Au-Pd surfaces and nanoparticles ${ }^{28-31}$. This has been attributed to negative charge build-up on the $\mathrm{Au}$ atoms on $\mathrm{Au}-\mathrm{Pd}$ alloy formation as a result of $\mathrm{Au}$ (2.4) being more electronegative than $\mathrm{Pd}(2.2)^{30}$. The positive shift of $+0.3 \mathrm{eV}$ from 340.6 to $340.9 \mathrm{eV}$ seen for the Pd $3 \mathrm{~d}_{3 / 2}$ peak (Fig. $6 \mathrm{~b}$ ) is in line with this and suggests deposition of some positive charge onto the Pd atoms. Alternatively, the positive shift could also result from partial oxidation of Pd. It should be kept in mind that the EXAFS data show that Pd is predominantly present in $\mathrm{Au}-\mathrm{Pd}$ particles, but metallic $\mathrm{Pd}$ and $\mathrm{Pd}-\mathrm{O}$ species were also detected. The latter were also seen for $\mathrm{Au}-\mathrm{Pd} / \mathrm{SiO}_{2}$ catalysts $^{32}$. Indeed, both the $1 \% \mathrm{Au}-\mathrm{Pd} / \mathrm{TiO}_{2}\left(\mathrm{M}_{\mathrm{Im}}\right)$ and $1 \% \mathrm{Pd} / \mathrm{TiO}_{2}\left(\mathrm{M}_{\mathrm{Im}}\right)$ samples showed weak peaks at around 342.6 (ref. 27) and $337.2 \mathrm{eV}$ (ref. 33), confirming the presence of Pd oxide on the surface of both samples. The Ti $2 p$ and $O$ 1s XPS peaks were observed at the same BE for the Au, Pd and Au-Pd catalysts, suggesting a similar level of interaction between the metal and $\mathrm{TiO}_{2}$ support in these three catalyst materials (Supplementary Fig. 14).

For the Ru-based catalyst samples, the overlap of the $\mathrm{Ru} 3 \mathrm{~d}_{3 / 2}$ and $\mathrm{Ru}^{\mathrm{n}}+3 \mathrm{~d}_{5 / 2}$ XPS signals with the $\mathrm{C}$ 1s sample holder XPS signal (Fig. 6c) allows the metallic state of Ru to be studied only via the $\mathrm{Ru} 3 \mathrm{~d}_{5 / 2}$ XPS signal. Elmasides et al. ${ }^{34}$ previously reported this XPS peak to be at $280.1 \mathrm{eV}$ for $\mathrm{Ru}^{0}$ supported on $\mathrm{TiO}_{2}$. For $1 \% \mathrm{Ru} / \mathrm{TiO}_{2}\left(\mathrm{M}_{\mathrm{Im}}, 0 \mathrm{M} \mathrm{HCl}\right)$, a positive shift of $+0.8 \mathrm{eV}$ of the $\mathrm{Ru} 3 \mathrm{~d}_{5 / 2}$ signal to $280.9 \mathrm{eV}$ was observed, together with negative shifts of both the Ti 2p and O 1s XPS peaks; in addition, shoulder peaks appeared on the Ti $2 \mathrm{p}$ and $\mathrm{O}$ 1s XPS signals, which point at electron transfer from $\mathrm{Ru}$ to $\mathrm{TiO}_{2}$ with concomitant reduction of some of the $\mathrm{Ti}^{4+}$ into $\mathrm{Ti}^{3}{ }^{+}$. For the $\mathrm{Ru}-\mathrm{Pd}$ sample, the $\mathrm{Ru} 3 \mathrm{~d}_{5 / 2}$ peak is instead observed at $280.6 \mathrm{eV}$. This, together with the smaller changes in the $\mathrm{Ti} 2 \mathrm{p}$ and $\mathrm{O} 1 \mathrm{~s}$ XPS spectra (Supplementary Fig. 14), indicates that the interaction between $\mathrm{Ru}$ and $\mathrm{TiO}_{2}$ is weaker for the $\mathrm{Ru}-\mathrm{Pd}$ sample than in $1 \% \mathrm{Ru} / \mathrm{TiO}_{2}$ $\left(M_{\mathrm{Im}}, 0 \mathrm{M} \mathrm{HCl}\right)$. The Pd $3 \mathrm{~d}_{5 / 2}(+0.9 \mathrm{eV})$ and $\mathrm{Pd} 3 \mathrm{~d}_{3 / 2}(+1.0 \mathrm{eV})$ peaks furthermore show a positive shift and larger $\mathrm{Pd}$ oxide contribution compared with $1 \% \mathrm{Pd} / \mathrm{TiO}_{2}\left(M_{\mathrm{Im}}\right)$, indicative of highly dispersed and positively charged Pd species on the surface of the $1 \% \mathrm{Ru}-\mathrm{Pd} / \mathrm{TiO}_{2}\left(M_{\mathrm{Im}}\right)$ catalyst. EXAFS and XPS thus both show a more pronounced $\mathrm{Pd}-\mathrm{O}$ character in $1 \% \mathrm{Ru}-\mathrm{Pd} / \mathrm{TiO}_{2}$ $\left(\mathrm{M}_{\mathrm{Im}}\right)$. All this thus suggests that at the metal surface $\mathrm{Ru}$ is less 
positively charged as a result of a weaker interaction of $\mathrm{Ru}$ with the support, while $\mathrm{Pd}$ is highly positively charged with some $\mathrm{Pd}-\mathrm{O}$ character at the surface. Note that no residual $\mathrm{Cl}$ was detected by XPS in any of the monometallic and bimetallic $M_{\mathrm{Im}}$ catalysts under investigation, except for a trace amount in the $1 \% \mathrm{Au} / \mathrm{TiO}_{2}$ $\left(M_{\text {Im }}\right)$ sample.

CO FT-IR spectroscopy. All mono- and bimetallic catalysts were also characterized by FT-IR spectroscopy after CO adsorption, see also Supplementary Figs 15-19. Figure 7a shows the changes in the FT-IR spectra of adsorbed CO over $1 \% \mathrm{Au}-\mathrm{Pd} / \mathrm{TiO}_{2}\left(M_{\mathrm{Im}}\right)$ at $87 \mathrm{~K}$ on stepwise increase in $\mathrm{CO}$ pressure. The three spectral features at 2,117, 2,081 and 2,000-1,900 $\mathrm{cm}^{-1}$, which are already detected at low $\mathrm{CO}$ pressures, can be assigned to linear Au-CO, linear Pd-CO and bridging $\mathrm{Pd}-\mathrm{CO}$ species, respectively ${ }^{35-40}$. Notably, a feature similar to the one at $2,081 \mathrm{~cm}^{-1}$ has been ascribed to CO linearly adsorbed on isolated Pd atoms in Au-Pd alloy films ${ }^{40}$. Furthermore, a red shift similar to the shift of the $\mathrm{Au}-\mathrm{CO}(\mathrm{L})$ feature at 2,117 to $2,114 \mathrm{~cm}^{-1}$ on increasing the $\mathrm{CO}$ pressure has also been seen in Au-Pd model catalyst systems ${ }^{39-42}$.

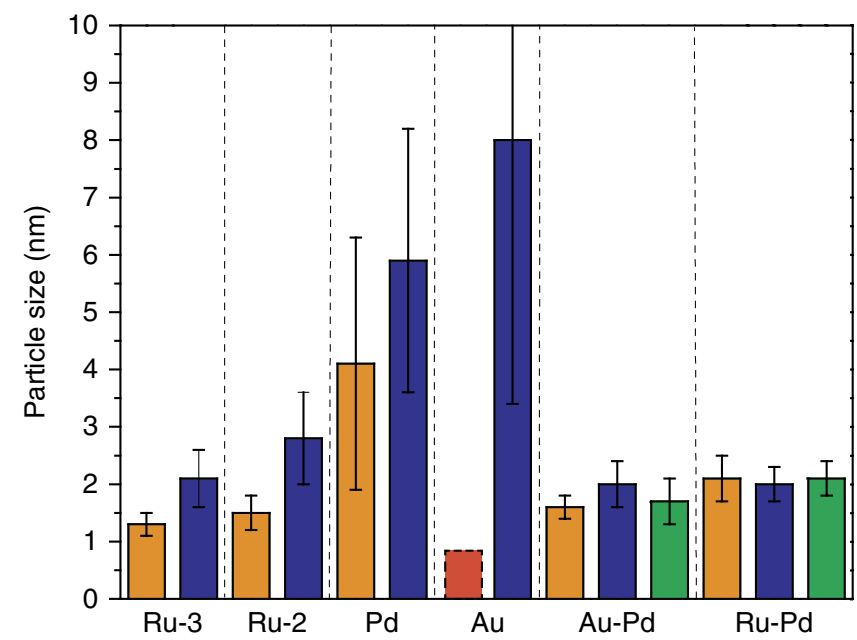

Figure 5 | Mean metal particle sizes for the fresh and spent catalysts. Orange bar = fresh catalyst; Blue bar = spent catalyst after 1 run; Green bar = spent catalyst after three consecutive runs. Ru-2 and Ru-3 corresponds to $1 \% \mathrm{Ru} / \mathrm{TiO}_{2}\left(M_{\mathrm{lm}}\right)$ and $1 \% \mathrm{Ru} / \mathrm{TiO}_{2}\left(M_{\mathrm{Im}}, \mathrm{OM} \mathrm{HCl}\right)$, respectively. The red, dashed bar shown for the fresh $1 \% \mathrm{Au} / \mathrm{TiO}_{2}\left(M_{\mathrm{Im}}\right)$ catalyst indicates that sub-nanometre Au particles, that is, of a size below the TEM detection limit, are present, together with larger submicron-sized ones. All catalysts were prepared by the $M_{\mathrm{Im}}$ synthesis method. The error bars represent the standard deviation based on the histogram statistics for at least 200 counts of particle diameters.
The simultaneous blue-shift of the $\mathrm{Pd}-\mathrm{CO}(\mathrm{L})$ signal indicates strong electronic interaction between these $\mathrm{Au}-\mathrm{CO}(\mathrm{L})$ and $\mathrm{Pd}-$ $\mathrm{CO}(\mathrm{L})$ species and again point at the direct adjacency of $\mathrm{Au}$ and Pd atoms. The new, weakly adsorbed CO species that is observed at $2,103 \mathrm{~cm}^{-1}$ at higher $p_{\mathrm{CO}}$ can be assigned to $\mathrm{CO}$ adsorption on isolated monometallic Pd species, which were also detected by STEM $^{35,40,43}$.

Taken together, the partial negative charge on $\mathrm{Au}$ as seen in XPS, the confirmation of an Au-Pd nano-alloy by STEM and EXAFS, the evidence obtained by FT-IR for isolated Pd species and the close proximity of $\mathrm{Au}$ and $\mathrm{Pd}$, all suggest efficient mixing and electron transfer from $\mathrm{Pd}$ to $\mathrm{Au}$ in the $\mathrm{Au}-\mathrm{Pd}$ catalyst. The fact that $\mathrm{CO}$ adsorption on $\mathrm{Pd}$ is much stronger on Au-Pd alloy formation (Fig. 7c, d), also seen before with a model Au-Pd catalyst ${ }^{40}$, provides further evidence of the strong electronic modification of Pd upon nano-alloy formation with Au. This electronic modification of $\mathrm{Pd}$ is considered the cause of the marked increase in LA hydrogenation activity ${ }^{13,44}$. Changes in surface reactivity of bimetallic nano-alloys, such as the one observed for the Au-Pd system, is thought to be the consequence of a combination of electronic and geometric effects. Indeed, to disentangle the relative contributions to alloying is a difficult task. For Au-Pd systems, DFT studies have suggested that on incorporation of larger $\mathrm{Au}$ atoms in the Pd lattice (with has a smaller lattice constant than $\mathrm{Au}$ ), a lattice mismatch results in tensile strain in the structure of these Au-Pd nano-alloys. This strain generally induces changes in the ability of this metal (active) site to form bonds to adsorbed species or, in other words, changes the reactivity of the metal (active) sites ${ }^{45}$. This change in activity can be thought to be the result of a change in width and centre of the d-band centres (for both $\mathrm{Au}$ and $\mathrm{Pd}$ ) on alloying ${ }^{46}$. In this case, a narrowing and upward shift of the d-band of Pd due to the tensile strain would then result in enhanced chemical reactivity of these surface atoms. Further computational studies are, however, needed to understand what is the exact cause of the synergistic effect reported here.

Differentiation of the adsorbed species on $1 \% \mathrm{Ru}-\mathrm{Pd} / \mathrm{TiO}_{2}$ $\left(M_{\mathrm{Im}}\right)$ proved more difficult, as a result of overlapping of bands of $\mathrm{CO}$ adsorbed on Ru and Pd. Furthermore, little electron transfer between $\mathrm{Ru}$ and $\mathrm{Pd}$ is expected given that the electronegativity of the two is the same. In line with the XPS and EXAFS data, the FTIR spectra of Fig. $7 \mathrm{~b}$ do, nonetheless, support that $\mathrm{Ru}$ and oxidized $\mathrm{Pd}$ are present in a $\mathrm{Ru}-\mathrm{Pd}$ nano-alloy catalyst materials.

Notably, less CO is adsorbed on the Ru-Pd catalyst than on $1 \%$ $\mathrm{Ru} / \mathrm{TiO}_{2}\left(M_{\mathrm{Im}}, 0 \mathrm{M} \mathrm{HCl}\right)$ at $473 \mathrm{~K}$ and under high vacuum, as can be seen from the attenuated intensity of the $\mathrm{Ru}^{\delta+}-\mathrm{CO}(\mathrm{L})$ vibration at $2,075 \mathrm{~cm}^{-1}$ in the FT-IR spectra of Supplementary Figs $18,19^{24-26}$. This indicates a weakened interaction between $\mathrm{Ru}$ and $\mathrm{TiO}_{2}$ in the bimetallic sample, as is also evidenced by the longer $\mathrm{Ru}-\mathrm{O}$ bond lengths found by EXAFS and the more limited

Table 1 | EXAFS parameters.

\begin{tabular}{|c|c|c|c|c|c|c|c|c|c|c|c|c|}
\hline Sample & $\begin{array}{c}\text { Au-Au R } \\
(\AA)\end{array}$ & $(\mathrm{N})$ & $\begin{array}{l}2 \sigma^{2} \\
\left(\AA^{2}\right)\end{array}$ & $\begin{array}{c}\text { Au-Pd R } \\
(\AA)\end{array}$ & (N) & $\begin{array}{l}2 \sigma^{2} \\
\left(\AA^{2}\right)\end{array}$ & $\begin{array}{c}\text { Pd-Pd R } \\
(\AA)\end{array}$ & (N) & $\begin{array}{l}2 \sigma^{2} \\
\left(\AA^{2}\right)\end{array}$ & $\begin{array}{c}\text { Pd-Au R } \\
(\AA)\end{array}$ & (N) & $\begin{array}{l}2 \sigma^{2} \\
\left(\AA^{2}\right)\end{array}$ \\
\hline \multirow{2}{*}{$\begin{array}{l}1 \% \mathrm{AuPd} / \mathrm{TiO}_{2}\left(\mathrm{M}_{\mathrm{lm}}\right) \\
1 \% \mathrm{Au} / \mathrm{TiO}_{2}\left(\mathrm{M}_{\mathrm{lm}}\right)\end{array}$} & $\begin{array}{l}2.80 \\
2.84\end{array}$ & $\begin{array}{r}4.8 \\
10.0\end{array}$ & $\begin{array}{l}0.017 \\
0.017\end{array}$ & 2.77 & 2.5 & 0.014 & 2.75 & 1 & 0.014 & 2.78 & 2.0 & 0.016 \\
\hline & Ru-O & & & Ru-Ru (Pd) & & & Pd-O & & & Pd-Pd (Ru) & & \\
\hline $\begin{array}{l}1 \% \mathrm{RuPd} / \mathrm{TiO}_{2}\left(M_{\mathrm{lm}}\right) \\
1 \% \mathrm{Pd} / \mathrm{TiO}_{2}\left(M_{\mathrm{Im}}\right) \\
1 \% \mathrm{Ru} / \mathrm{TiO}_{2}\left(M_{\mathrm{Im}} 0 \mathrm{M} \mathrm{HCl}\right)\end{array}$ & 1.96 & 3.0 & 0.011 & 2.69 & 2 & $\begin{array}{l}0.023 \\
0.013\end{array}$ & $\begin{array}{l}2.0 \\
2.0\end{array}$ & $\begin{array}{l}1.7 \\
2.0\end{array}$ & $\begin{array}{l}0.009 \\
0.010\end{array}$ & $\begin{array}{l}2.72 \\
2.73\end{array}$ & $\begin{array}{l}1.8 \\
4.0\end{array}$ & $\begin{array}{l}0.019 \\
0.019\end{array}$ \\
\hline
\end{tabular}

EXAFS parameters for the monometallic and bimetallic catalysts determined from an analysis of the $\mathrm{Au} \mathrm{L}_{3}, \mathrm{Pd} \mathrm{K}$ and Ru K edges. $E_{\mathrm{f}} \sim \pm 15 \mathrm{eV} ; R$-values for all data range from $28-38 \%$; Afac values, 0.94 $(\mathrm{Pd} / \mathrm{Ru})$ and $0.98 \mathrm{Au}$. The Debye-Waller factors were initially determined from the $1 \% \mathrm{Au}-\mathrm{Pd} / \mathrm{TiO}_{2}\left(\mathrm{M}_{\mathrm{lm}}\right)$ sample and not refined for the remaining Au-Pd samples. For sample $1 \% \mathrm{AuPd} / \mathrm{TiO} 2\left(\mathrm{M}_{\mathrm{lm}}\right)$ a Pd$\mathrm{O}$ contribution is also present at $2.02 \AA$ with $N=1$ and $2 \sigma^{2}=0.0013 \AA^{2}$. 

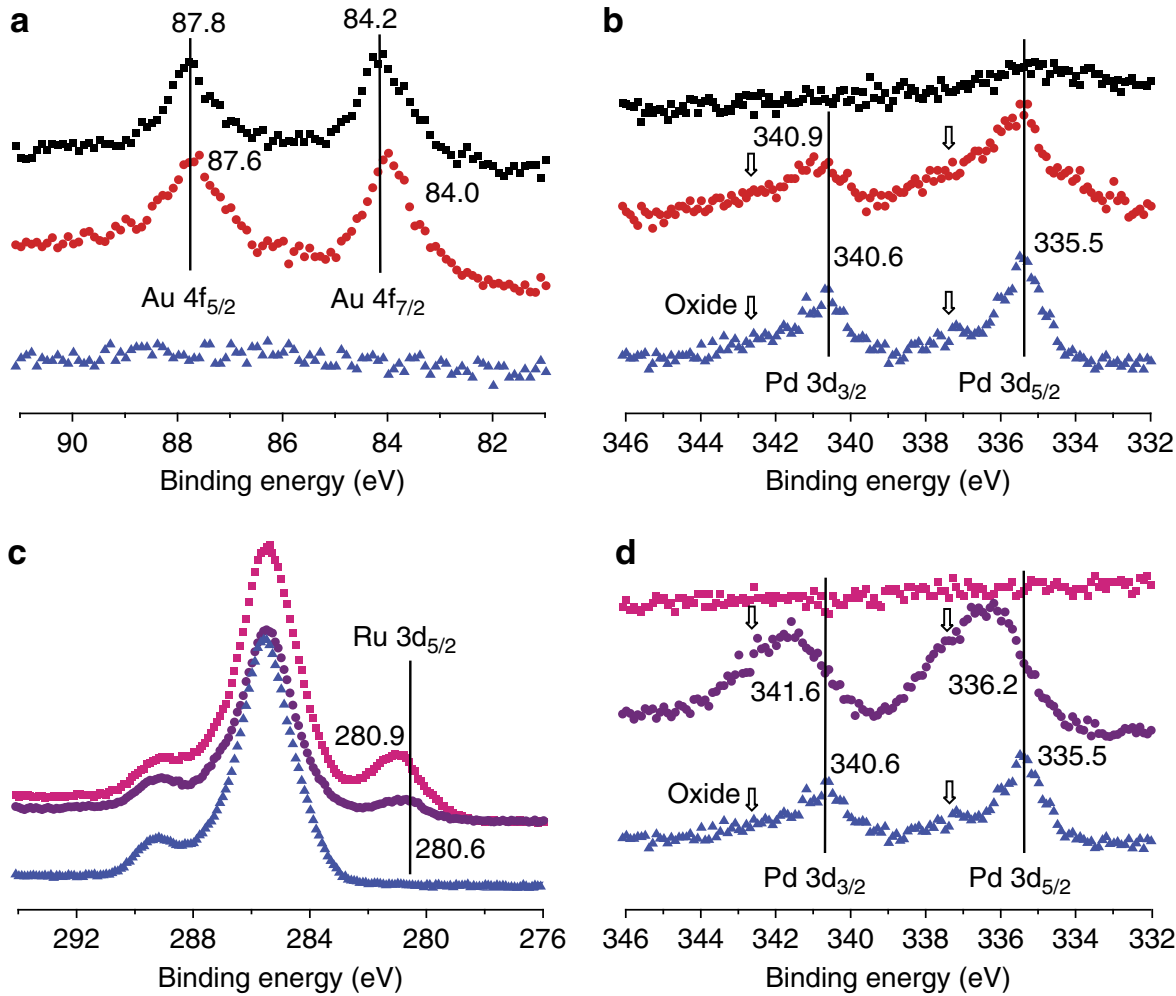

Figure 6 | XPS spectra of selected monometallic and bimetallic $\boldsymbol{M}_{\mathbf{l m}}$ catalysts. (a) Au $4 \mathrm{f}$ spectral region. (b) Pd $3 d$ spectral region. The arrows indicate the presence of some Pd oxide in the sample. (c) Ru 3d spectral region. (d) Pd 3d spectral region. Catalyst sample codes are as follows: (pink squares) 1\%

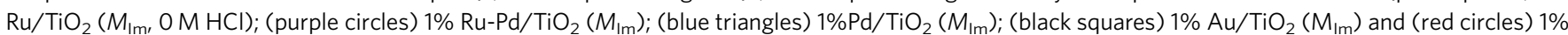
AuPd/TiO $2\left(M_{I m}\right)$.
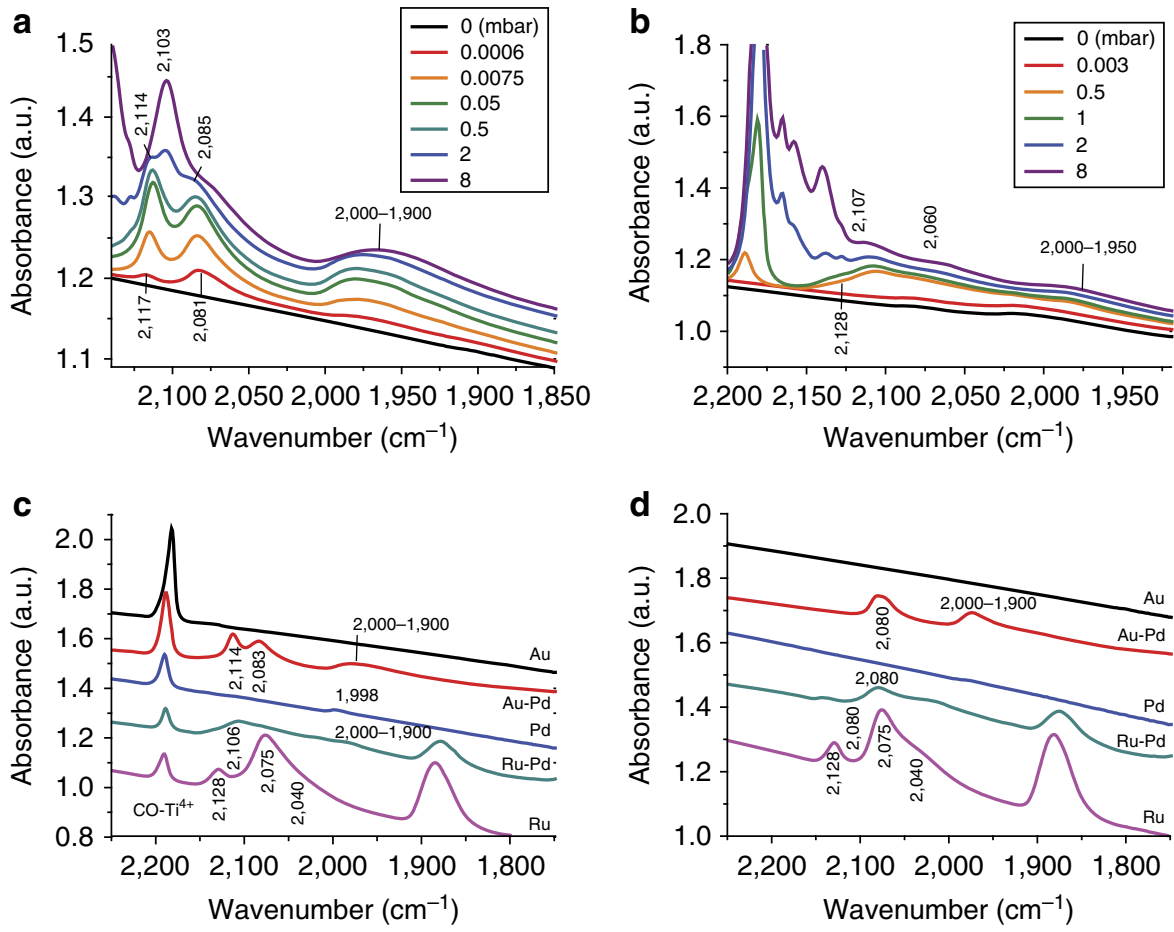

Figure 7 | FT-IR spectra of $\mathbf{C O}$ adsorption and desorption on monometallic and bimetallic catalysts. (a) $1 \% \mathrm{Au}-\mathrm{Pd} / \mathrm{TiO} \mathrm{O}_{2}\left(\mathrm{M}_{\mathrm{Im}}\right)$ catalyst measured at $87 \mathrm{~K}$ at different $\mathrm{CO}$ pressures. (b) $1 \% \mathrm{Ru}-\mathrm{Pd} / \mathrm{TiO}_{2}\left(\mathrm{M}_{\mathrm{Im}}\right)$ catalyst measured at $87 \mathrm{~K}$ and different $\mathrm{CO}$ pressures. (c) $\mathrm{FT}$-IR spectra measured at $87 \mathrm{~K}$ and a partial CO pressure of 0.5 mbar of $1 \% \mathrm{Au} / \mathrm{TiO}_{2}\left(\mathrm{M}_{\mathrm{Im}}\right), 1 \% \mathrm{Pd} / \mathrm{TiO}_{2}\left(M_{\mathrm{Im}}\right), 1 \% \mathrm{Ru} / \mathrm{TiO}_{2}\left(\mathrm{M}_{\mathrm{Im}}, 0 \mathrm{M} \mathrm{HCl}\right), 1 \% \mathrm{Au}-\mathrm{Pd} / \mathrm{TiO}_{2}\left(\mathrm{M}_{\mathrm{Im}}\right)$ and $1 \% \mathrm{Ru}-\mathrm{Pd} / \mathrm{TiO} 2\left(\mathrm{M}_{\mathrm{lm}}\right)$ catalysts (d) at $87 \mathrm{~K}$ and $p_{\mathrm{CO}}=0.5 \mathrm{mbar}$; (d) FT-IR spectra measured at $473 \mathrm{~K}$ and a $p_{\mathrm{CO}}$ of $\sim 10^{-6} \mathrm{mbar}$ for the same set of catalysts as under $\mathbf{c}$. 
partial Ti reduction seen by XPS (Fig. 6, Supplementary Fig. 14 and Supplementary Table 4). These observations provide further insight into the improved performance of the $1 \% \mathrm{Ru}-\mathrm{Pd} /$ $\mathrm{TiO}_{2}\left(M_{\mathrm{Im}}\right)$ catalyst. First, the lack of sintering of $\mathrm{Ru}$ is suggested to be the result of a stabilization effect ${ }^{29,44}$, in which the presence of Pd species on the surface dilutes and isolates the active $\mathrm{Ru}$ sites; second, the catalyst can maintain its excellent GVL selectivity, as the weakened interaction between support and metal effectively 'switches-off any consecutive hydrogenation reactions.

Finally, fitting the $\mathrm{CO}$ adsorption data with a Temkin-Pyzhev adsorption isotherm $\left(\Theta=\mathrm{a} \ln \left(\mathrm{b} \times p_{\mathrm{CO}}\right)\right.$ where $\Theta$ is the coverage of CO, and a and b are constants), as illustrated in Supplementary Fig. 20, revealed a semi-quantitative correlation of CO adsorption with catalytic activity. Indeed, Fig. 8 shows that the initial rate of LA to GVL transformation for three different catalysts was found to correlate well with the amount of linearly $\mathrm{CO}$ adsorbed at the actual reaction temperature. Similar $\mathrm{CO}$ extinction coefficients were assumed for the linearly adsorbed $\mathrm{CO}$ species detected in the $2,100-2,000 \mathrm{~cm}^{-1}$. Interestingly, Fan et al. ${ }^{47}$ reported that small amounts of $\mathrm{CO}(\sim 1,000$ p.p.m.) already had a significant, negative effect on LA hydrogenation over supported platinumgroup metals, suggesting that the active sites for both $\mathrm{CO}$ adsorption and LA to GVL hydrogenation are indeed related. Consequently, we believe that $\mathrm{CO}$ adsorption, as measured by FTIR, can be used to semi-quantitatively predict catalyst activity for this reaction. Further studies, spanning a broader range of catalysts, are required to further substantiate this correlation.

\section{Discussion}

In summary, $\mathrm{TiO}_{2}$-supported bimetallic $\mathrm{Au}-\mathrm{Pd}$ and $\mathrm{Ru}-\mathrm{Pd}$ nanoalloy catalysts were synthesized by a modified impregnation $\left(M_{\mathrm{Im}}\right)$ method and shown to be highly active in the hydrogenation of levulinic acid to $\gamma$-valerolactone. Alloying was found to have two distinct effects. First, an electronic effect is seen for $1 \%$ $\mathrm{Au}-\mathrm{Pd} / \mathrm{TiO}_{2}$, with catalytic activity resulting from the modification of the electronic properties of Pd upon alloying with $\mathrm{Au}$. The combination of two relatively inactive metals thus led to a remarkable increase in catalytic activity. Second, a stabilization effect is seen for $1 \% \mathrm{Ru}-\mathrm{Pd} / \mathrm{TiO}_{2}$, with $\mathrm{Pd}$ species diluting and isolating the active $\mathrm{Ru}$ sites, resulting in excellent selectivity to GVL by switching-off consecutive hydrogenation reactions. Both the $\mathrm{Ru}-\mathrm{Pd}$ and $\mathrm{Au}-\mathrm{Pd}$ nano-alloy catalysts furthermore showed

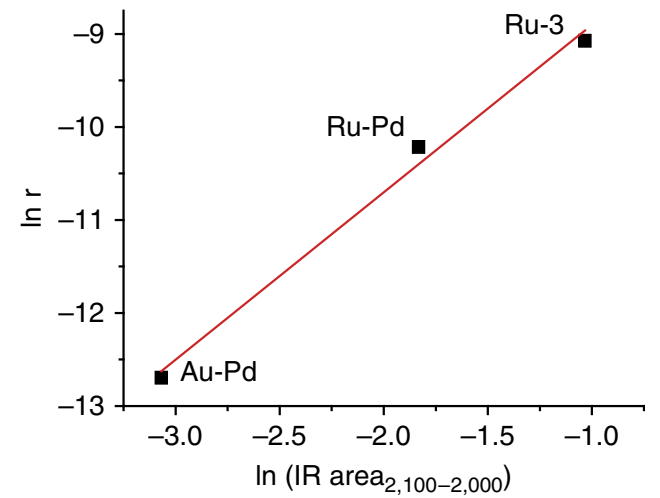

Figure 8 | Relationship between reaction rate and adsorbed linear CO species for different catalysts. Plot of the natural logarithm of reaction rate versus amount of adsorbed linear $\mathrm{CO}$ species for different catalysts at $473 \mathrm{~K}$, the reaction temperature for the LA to GVL conversion. The initial reaction rate is expressed in $\mathrm{mols}^{-1}$ and the amount of linearly adsorbed $\mathrm{CO}$ was determined by integration of the spectra between $2,100 \mathrm{~cm}^{-1}$ and $2,000 \mathrm{~cm}^{-1}$, normalized by pellet weight. excellent stability even after three consecutive catalytic runs. Finally, a variation in the synthesis method of the benchmark monometallic $1 \% \mathrm{Ru} / \mathrm{TiO}_{2}$ catalyst led to the discovery of an exceptionally active catalyst $\left(51.7 \mathrm{~mol}_{\mathrm{GVL}} \mathrm{g}^{-1}{ }_{\text {metal }} \mathrm{h}^{-1}\right.$ and $\mathrm{TOF}=2.0 \mathrm{~s}^{-1}$ ). In contrast to the bimetallic Ru-Pd catalyst, limited sintering was observed though for both monometallic $\mathrm{Ru}$ catalysts, that is, the exceptionally active and the MIm prepared one. These findings open up new possibilities for the application of bimetallic catalysts, prepared using carefully designed synthesis strategies, in bio-based fuel and chemicals production. Future studies should now be directed at an assessment of longer-term stability, that is, under continuous-flow conditions, as well as at a more detailed understanding of the two distinct effects of metal alloying, for example, by computational means.

\section{Methods}

Catalyst preparation. All the supported monometallic and bimetallic catalysts were prepared from their corresponding metal chloride precursors via a modified wet-impregnation method that involves using an excess of chloride anions $\left(M_{\mathrm{Im}}\right)^{20}$ All catalysts prepared by this modified impregnation method are represented as $M_{\mathrm{Im}}$ catalysts. The $M_{\mathrm{Im}}$ method entails the use of the following precursor solutions: $\mathrm{HAuCl}_{4} \cdot \mathrm{xH}_{2} \mathrm{O}$ ( $>99.9 \%$, Sigma Aldrich) was dissolved in deionized water to form a solution with a Au concentration of $9.34 \mathrm{mg} \mathrm{ml}^{-1}$. $\mathrm{RuCl}_{3}(99.9 \%$, Acros

Chemicals) was dissolved in deionized water to form an aqueous solution with a $\mathrm{Ru}$ concentration of $5.28 \mathrm{mg} \mathrm{ml}^{-1}$. The $\mathrm{PdCl}_{2}$ salt ( $<99 \%$, Sigma Aldrich) was dissolved in $0.5 \mathrm{M} \mathrm{HCl}$ under vigorous stirring and gentle warming to obtain a solution with a resultant $\mathrm{Pd}$ concentration of $3.02 \mathrm{mg} \mathrm{ml}^{-1}$. This solution was slowly cooled and used as the Pd precursor.

In a typical catalyst synthesis, the requisite amount of precursor solution(s) was charged into a clean $50 \mathrm{ml}$ round bottomed flask fitted with a magnetic stirrer, after which the requisite amount of concentrated $\mathrm{HCl}(37.5 \%)$ was added and the volume of the precursor/ $\mathrm{HCl}$ solution finally adjusted to $25 \mathrm{ml}$ to obtain a final $\mathrm{HCl}$ concentration of $0.5 \mathrm{M}$ in deionized water. The round bottom flask was submerged in a temperature-controlled oil bath and the mixture was then agitated vigorously at $298 \mathrm{~K}$ using a hot plate stirrer. To the stirred precursor solution, the requisite amount of the support (P-25 $\mathrm{TiO}_{2}$, Evonik-Degussa) was added very slowly with constant stirring at $298 \mathrm{~K}$ over nearly $30 \mathrm{~min}$. After complete support addition, the slurry was stirred vigorously and then the temperature was raised to $358 \mathrm{~K}$. The slurry was stirred at this temperature overnight until all water had evaporated. The solid powder obtained, denoted as the 'dried sample', was ground thoroughly and then reduced in a furnace at $723 \mathrm{~K}\left(\sim 2 \mathrm{Kmin}^{-1}\right.$ ramp rate $)$ under a flow of $5 \%$ $\mathrm{H}_{2} / \mathrm{He}$ for $4 \mathrm{~h}$. All the monometallic and bimetallic catalysts were prepared with a $1 \mathrm{wt} \%$ (total) metal content on a $1 \mathrm{~g}$ scale and in the case of the bimetallic $M_{\mathrm{Im}}$ catalysts, the two metals were added in an equimolar metal ratio.

The $1 \% \mathrm{Ru} / \mathrm{TiO}_{2}\left(M_{\mathrm{Im}}, 0 \mathrm{M} \mathrm{HCl}\right)$ catalyst, without the addition of $\mathrm{HCl}$, was prepared with similar methodology. The requisite amount of the precursor $\mathrm{RuCl}_{3}$ solution was charged into a clean $50 \mathrm{ml}$ round-bottomed flask fitted with a magnetic stirrer and then the solution was made up to $25 \mathrm{ml}$ with deionized water, and no $\mathrm{HCl}$ was added. Subsequent steps were identical to those mentioned in the previous $M_{\mathrm{Im}}$ method.

Catalyst testing. All the catalytic hydrogenation reactions of LA to GVL were performed in dioxane using a high-pressure autoclave reactor fitted with an overhead stirrer. The reactions were run in a $100 \mathrm{ml}$ Parr batch autoclave at a temperature of $473 \mathrm{~K}$ for $10 \mathrm{~h}$ using a hydrogen pressure of 40 bar and a stirring speed of 1,600 r.p.m. Reactions were performed with $10 \mathrm{wt} \%$ levulinic acid $(6.0 \mathrm{~g}$, $51.7 \mathrm{mmol})$ in dioxane $(54 \mathrm{~g})$ with $1 \mathrm{wt} \%$ of catalyst $(0.6 \mathrm{~g})$. One millilitre of solution was sampled at various intervals during the reaction. Before the reaction, the batch autoclave reactor was loaded with catalyst, substrate and solvent, purged three times with argon after which the reaction mixture was heated to reaction temperature and charged with $\mathrm{H}_{2}$ to 40 bar. This was taken as the starting point of the reaction. After the reaction was cooled to room temperature, the $\mathrm{H}_{2}$ pressure was released and $2 \mathrm{wt} \%$ anisole was added as an internal standard. The catalyst was separated by centrifugation, filtration and finally washed with acetone.

The reaction products were analysed using a Shimadzu GC-2010 A gas chromatograph equipped with a CP-WAX $57-\mathrm{CB}$ column $(25 \mathrm{~m} \times 0.2 \mathrm{~mm} \times 0.2 \mu \mathrm{m})$ and FID detector. Products were identified with a GC - MS from Shimadzu with a CP-WAX 57CB column $(30 \mathrm{~m} \times 0.2 \mathrm{~mm} \times 0.2 \mu \mathrm{m})$. The gas phase reaction products were analysed by an on-line dual channel Varian CP4900 micro-GC equipped with a COX column and TCD detector, for analysis of $\mathrm{H}_{2}, \mathrm{CO}_{2}, \mathrm{CO}$ and $\mathrm{CH}_{4}$. The turnover frequency (TOF) values were calculated as follows: TOF $=$ initial rate/ (metal amount $\times$ dispersion of metal $\times$ time). The influence of external mass transfer limitations on catalysis was studied as a function of stirrer speed with the benchmark $\mathrm{Ru} / \mathrm{C}$ catalyst. Such limitations could be overcome if stirring speeds were set higher than 900 r.p.m. and all experiments reported in this article were subsequently run at a stirrer speed of 1,600 r.p.m. 
Catalyst characterization. Samples for examination by scanning transmission electron microscopy (STEM) were prepared by dispersing the dry catalyst powder onto a holey carbon film supported by a 300 mesh copper TEM grid. STEM high angle annular dark field (HAADF) images of the supported metal nanoparticles were obtained using an aberration corrected JEM ARM-200 F STEM operating at $200 \mathrm{kV}$. X-ray energy dispersive (XEDS) spectra were acquired from individual metal nanoparticles $>1 \mathrm{~nm}$ in size by rastering the beam over the entire metal particle, while using a JEOL Centurio 0.9sr silicon drift detector. The sample powders were also dispersed onto an Al-stub and examined in SE and backscatter mode in a Hitachi 4300LV scanning electron microscope (SEM) equipped with an EDAX energy dispersive X-ray spectrometer to determine if there were any $\mu \mathrm{m}$-scale metal particles present.

Transmission electron microscopy (TEM) measurements were conducted in bright field imaging mode using a Tecnai 20FEG transmission electron microscope operating at $200 \mathrm{kV}$. The mean Ru particle diameters were calculated by determining the size of more than 200 particles per sample using iTEM software (soft Imaging System GmbH). For non-symmetrical particle shapes, both the largest and shortest diameter was measured to obtain an average value.

Metal dispersion has been estimated by TEM/STEM: $\mathrm{D}=6 \times\left(v_{\mathrm{m}} / a_{\mathrm{m}}\right) / d$, where $v_{\mathrm{m}}$ is bulk metal atomic density of $\mathrm{Ru}\left(13.65 \times 10^{-3} \mathrm{~nm}^{3}\right), \operatorname{Pd}\left(14.7 \times 10^{-3} \mathrm{~nm}^{3}\right)$ and $\mathrm{Au}\left(16.94 \times 10^{-3} \mathrm{~nm}^{3}\right), a_{\mathrm{m}}$ is the surface area occupied by an atom on a polycrystalline surface of $\mathrm{Ru}\left(6.35 \times 10^{-2} \mathrm{~nm}^{2}\right), \mathrm{Pd}\left(7.93 \times 10^{-2} \mathrm{~nm}^{2}\right)$ and $\mathrm{Au}$ $\left(8.75 \times 10^{-2} \mathrm{~nm}^{2}\right)$ and $d$ is the cluster size of metal determined by TEM and STEM.

$\mathrm{X}$-ray absorption fine structure (XAFS) measurements were performed on station BM26A and BM23 at the ESRF ${ }^{48}$. The measurements were carried out in air on self-supporting wafers in transmission mode using a $\mathrm{Si}(111)$ monochromator at the $\mathrm{Au} \mathrm{L} \mathrm{L}_{3}$-edge, $\mathrm{Pd} \mathrm{K}$-edge and Ru K-edge with the respective monometallic foils used as reference materials. All data were subjected to background correction using Athena (that is, IFFEFFIT software package) followed by either single or dual shell EXAFS fitting analyses performed using the DL-EXCURV program ${ }^{49,50}$

$\mathrm{X}$-ray photoelectron spectroscopy (XPS) measurements were carried out on a Thermo Scientific K-Alpha, equipped with a monochromatic small-spot X-ray source and a $180^{\circ}$ double focusing hemispherical analyser with a 128-channel detector. Spectra were obtained using an aluminium anode $\left(\mathrm{Al} K_{\alpha}=1486.6 \mathrm{eV}\right)$ operating at $72 \mathrm{~W}$ and a spot size of $400 \mu \mathrm{m}$. Survey scans were measured at a constant pass energy of $200 \mathrm{eV}$ and more detailed region scans at a pass energy of $50 \mathrm{eV}$. The background pressure of the system was $2 \times 10^{-9} \mathrm{mbar}$, and during measurement it was $3 \times 10^{-7} \mathrm{mbar}$ (of argon) because of the charge compensation dual beam source.

$\mathrm{N}_{2}$ physisorption isotherms were recorded to determine surface areas and pore volumes using a Micromeritics Tristar 3000 set-up operating at $77 \mathrm{~K}$. Bimetallic catalysts were outgassed for $12 \mathrm{~h}$ at $473 \mathrm{~K}$ in a nitrogen flow before the physisorption measurements. BET surface areas were determined using 10 points between 0.06 and 0.25 . Micropore volumes $\left(\mathrm{cm}^{3} \mathrm{~g}^{-1}\right)$ were determined by $t$-plot analysis for $t$ between 3.5 and $5.0 \AA$ to ensure inclusion of the minimum required pressure points.

FT-IR spectra were recorded on a Perkin-Elmer 2000 instrument with each spectrum consisting of 25 scans recorded at a resolution of $4 \mathrm{~cm}^{-1}$. Self-supported catalyst wafers $(37 \pm 10 \mathrm{mg}$ per $16 \mathrm{~mm})$ were pressed at $3 \mathrm{kbar}$ pressure for $10 \mathrm{~s}$. The wafer was placed inside a synchrotron cell with a $\mathrm{CaF}_{2}$ window. The cell was evacuated to $10^{-6} \mathrm{mbar}$, and the sample was subsequently dried at $573 \mathrm{~K}$ $\left(3 \mathrm{~K} \mathrm{~min}^{-1}\right)$ for $1 \mathrm{~h}$. The cell was cooled down to $87 \mathrm{~K}$ with liquid nitrogen and connected to a gas chamber that permitted adjustment of the pressure of $\mathrm{CO}$ injected into the cell. $\mathrm{CO}$ adsorption was studied at $87 \mathrm{~K}$ at stepwise increasing pressures with fresh catalysts previously reduced in $\mathrm{H}_{2}$ at $723 \mathrm{~K}$. CO desorption was also studied at $87 \mathrm{~K}$ during the evacuation process, and followed by temperature programmed desorption $\left(3 \mathrm{~K} \mathrm{~min}^{-1}\right)$ from 87 to $573 \mathrm{~K}$ for $30 \mathrm{~min}$ under high-vacuum conditions $\left(\sim 10^{-6} \mathrm{mbar}\right)$.

\section{References}

1. Bozell, J. J. \& Petersen, G. R. Technology development for the production of biobased products from biorefinery carbohydrates - the US Department of Energy's "Top 10" revisited. Green Chem. 12, 539-554 (2010).

2. Bozell, J. J. et al. Production of levulinic acid and use as a platform chemical for derived products. Resour. Conserv. Recyc. 28, 227-239 (2000).

3. Rackemann, D. W. \& Doherty, W. O. S. The conversion of lignocellulosics to levulinic acid. Biofuels Bioprod. Bioref. 5, 198-214 (2011).

4. Girisuta, B., Janssen, L. P. B. M. \& Heeres, H. J. Kinetic study on the acidcatalyzed hydrolysis of cellulose to levulinic acid. Ind. Eng. Chem. Res. 46, 1696-1708 (2007).

5. Pace, V. et al. 2-Methyltetrahydrofuran (2-MeTHF): A biomass-derived solvent with broad application in organic chemistry. ChemSusChem. 5, 1369-1379 (2012).

6. Bond, J. Q. et al. Integrated catalytic conversion of $\gamma$-valerolactone to liquid alkenes for transportation fuels. Science 327, 1110-1114 (2010).

7. Lange, J.-P. et al. Valeric biofuels: A platform of cellulosic transportation fuels. Angew. Chem. Int. Ed. 49, 4479-4483 (2010).

8. Serrano-Ruiz, J. C., Wang, D. \& Dumesic, J. A. Catalytic upgrading of levulinic acid to 5-nonanone. Green Chem. 12, 574-577 (2010).
9. Alonso, D. M., Wettstein, S. G. \& Dumesic, J. A. Gamma-valerolactone, a sustainable platform molecule derived from lignocellulosic biomass. Green Chem. 15, 584-595 (2013).

10. Wright, W. R. H. \& Palkovits, R. Development of heterogeneous catalysts for the conversion of levulinic acid to $\gamma$-valerolactone. ChemSusChem 5, 1657-1667 (2012).

11. Primo, A., Concepcion, P. \& Corma, A. Synergy between the metal nanoparticles and the support for the hydrogenation of functionalized carboxylic acids to diols on $\mathrm{Ru} / \mathrm{TiO}_{2}$. Chem. Commun. 47, 3613-3615 (2011).

12. Luo, W. et al. Ruthenium-catalyzed hydrogenation of levulinic acid: Influence of the support and solvent on catalyst selectivity and stability. J. Catal. 301, 175-186 (2013).

13. Alonso, D. M., Wettstein, S. G. \& Dumesic, J. A. Bimetallic catalysts for upgrading of biomass to fuels and chemicals. Chem. Soc. Rev. 41, 8075-8098 (2012).

14. Sankar, M. et al. Designing bimetallic catalysts for a green and sustainable future. Chem. Soc. Rev. 41, 8099-8139 (2012).

15. Braden, D. J. et al. Production of liquid hydrocarbon fuels by catalytic conversion of biomass-derived levulinic acid. Green Chem. 13, 1755-1765 (2011).

16. Wettstein, S. G. et al. Ru-Sn bimetallic catalysts for selective hydrogenation of levulinic acid to $\gamma$-valerolactone. Appl. Catal. B: Environ. 117-118, 321-329 (2012).

17. Yang, Y., Gao, G., Zhang, X. \& Li, F. Facile fabrication of composition-tuned $\mathrm{Ru}-\mathrm{Ni}$ bimetallics in ordered mesoporous carbon for levulinic acid hydrogenation. ACS Catal. 4, 1419-1425 (2014).

18. Shimizu, K., Kanno, S. \& Kona, K. Hydrogenation of levulinic acid to $\gamma$ valerolactone by $\mathrm{Ni}$ and $\mathrm{MoO}_{x}$ co-loaded carbon catalysts. Green Chem. 16, 3899-3903 (2014).

19. Paalanen, P., Weckhuysen, B. M. \& Sankar, M. Progress in controlling the size, composition and nanostructure of supported Au-Pd nanoparticles for catalytic applications. Catal. Sci. Technol. 3, 2869-2880 (2013).

20. Sankar, M. et al. Synthesis of stable ligand-free $\mathrm{Au}-\mathrm{Pd}$ nanoparticles using a simple excess anion method. ACS Nano 6, 6600-6613 (2012).

21. Morad, M. et al. Solvent-free aerobic oxidation of alcohols using supported Au-Pd nano-alloys prepared by a modified impregnation method. Catal. Sci. Technol. 4, 3120-3128 (2014).

22. McKale, A. G. et al. Generalized Ramsauer-Townsend effect in extended x-rayabsorption fine structure. Phys. Rev. B 38, 10919-10921 (1988).

23. Beale, A. M. \& Weckhuysen, B. M. EXAFS as a tool to interrogate the size and shape of mono and bimetallic catalyst nanoparticles. Phys. Chem. Chem. Phys. 12, 5562-5574 (2010).

24. Su, Y.-S., Lee, M.-Y. \& Lin, S. XPS and DRS of $\mathrm{Au} / \mathrm{TiO}_{2}$ catalysts: effect of pretreatment. Catal. Lett. 57, 49-53 (1999).

25. Zwijnenburg, A. et al. XPS and Mössbauer characterization of $\mathrm{Au} / \mathrm{TiO}_{2}$ propene epoxidation catalysts. J. Phys. Chem. B. 106, 9853-9862 (2002).

26. Schumacher, B., Plzak, V., Kinne, M. \& Behm, R. J. Highly active $\mathrm{Au} / \mathrm{TiO}_{2}$ catalysts for low-temperature $\mathrm{CO}$ oxidation: Preparation, conditioning and stability. Catal. Lett. 89, 109-114 (2003).

27. Horvath, D., Toth, L. \& Guczi, L. Au nanoparticles: effect of treatment on structure and catalytic activity of $\mathrm{Au} / \mathrm{Fe}_{2} \mathrm{O}_{3}$ catalyst prepared by coprecipitation. Catal. Lett. 67, 117-128 (2000).

28. Yi, C. W., Luo, K., Wei, T. \& Goodman, D. W. The composition and structure of Pd - Au surfaces. J. Phys. Chem. B 109, 18535-18540 (2005).

29. Liu, F., Wechsler, D. \& Zhang, P. Alloy-structure-dependent electronic behaviour and surface properties of Au-Pd nanoparticles. Chem. Phys. Lett. 461, 254-259 (2008).

30. Zhang, H. et al. Crown jewel catalyst: How neighbouring atoms affect the catalytic activity of top Au atoms? J. Catal. 305, 7-18 (2013).

31. Delannoy, L. et al. Surface Segregation of Pd from $\mathrm{TiO}_{2}$-supported Au-Pd nano-alloys under $\mathrm{CO}$ oxidation conditions observed in situ by ETEM and DRIFTS. ChemCatChem. 5, 2707-2716 (2013).

32. Qian, K. \& Huang, W. Au-Pd alloying-promoted thermal decomposition of $\mathrm{PdO}$ supported on $\mathrm{SiO}_{2}$ and its effect on the catalytic performance in $\mathrm{CO}$ oxidation. Catal. Today 164, 320-324 (2011).

33. Shen, W.-J., Okumura, M., Matsumura, Y. \& Haruta, M. The influence of the support on the activity and selectivity of Pd in CO hydrogenation. Appl. Catal. A: General 213, 225-232 (2001).

34. Elmasides, C., Kondarides, D. I., Grünert, W. \& Verykios, X. E. XPS and FT-IR study of $\mathrm{Ru} / \mathrm{Al}_{2} \mathrm{O}_{3}$ and $\mathrm{Ru} / \mathrm{TiO}_{2}$ catalysts: Reduction characteristics and interaction with a methane - oxygen mixture. J. Phys. Chem. B 103, 5227-5239 (1999).

35. Kuhn, W. K., Szanyi, J. \& Goodman, D. W. CO adsorption on Pd(111): the effects of temperature and pressure. Surf. Sci. 274, L611-L618 (1992).

36. Boccuzzi, F., Chiorino, A., Tsubota, S. \& Haruta, M. FT-IR study of carbon monoxide oxidation and scrambling at room temperature over $\mathrm{Au}$-supported on $\mathrm{ZnO}$ and $\mathrm{TiO}_{2}$. J. Phys. Chem. 100, 3625-3631 (1996). 
37. Gao, F., Wang, Y. \& Goodman, D. W. CO oxidation over Au-Pd(100) from ultrahigh vacuum to near-atmospheric pressures: The critical role of contiguous Pd atoms. J. Am. Chem. Soc. 131, 5734-5735 (2009).

38. Kolli, N. E., Delannoy, L. \& Louis, C. Bimetallic Au-Pd catalysts for selective hydrogenation of butadiene: Influence of the preparation method on catalytic properties. J. Catal. 297, 79-92 (2013).

39. Chen, M., Kumar, D., Yi, C.-W. \& Goodman, D. W. The promotional effect of Au in catalysis by Pd-Au. Science 310, 291-293 (2005).

40. Wei, T., Wang, J. \& Goodman, D. W. Characterization and chemical properties of Pd - Au alloy surfaces. J. Phys. Chem. C 111, 8781-8788 (2007).

41. Meier, D. C., Bukhtiyarov, V. \& Goodman, D. W. CO adsorption on $\mathrm{Au}(110)-(1 \times 2)$ : An IRAS investigation. J. Phys. Chem. B 107, 12668-12671 (2003).

42. Chen, M., Cai, Y., Yan, Z. \& Goodman, D. W. On the origin of the unique properties of supported Au nanoparticles. J. Am. Chem. Soc. 128, 6341-6346 (2006).

43. Gelin, P., Siedle, A. R. \& Yates, J. T. Stoichiometric adsorbate species interconversion processes in the chemisorbed layer. An infrared study of the carbon monoxide/Pd system. J. Phys. Chem. 88, 2978-2985 (1984).

44. Tao, F. Synthesis, catalysis, surface chemistry and structure of bimetallic nanocatalysts. Chem. Soc. Rev. 41, 7977-7979 (2012).

45. Mavrikakis, M., Hammer, B. \& Nørskov, J. K. Effect of strain on the reactivity of metal surfaces. Phys. Rev. Lett. 81, 2819-2822 (1998).

46. Ham, H. C., Hwang, G. S., Han, J., Nam, S. W. \& Lim, T. H. Geometric parameter effects on ensemble contributions to catalysis: $\mathrm{H}_{2} \mathrm{O}_{2}$ formation from $\mathrm{H}_{2}$ and $\mathrm{O}_{2}$ on Au-Pd alloys. A first principles study. J. Phys. Chem. C 114, 14922-14928 (2010).

47. Du, X.-L. et al. Hydrogen-independent reductive transformation of carbohydrate biomass into $\gamma$-valerolactone and pyrrolidone derivatives with supported Au catalysts. Angew. Chem. Int. Ed. 50, 7815-7819 (2011).

48. Nikitenko, S. et al. Implementation of a combined SAXS/WAXS/QEXAFS set-up for time-resolved in situ experiments. J. Synchrotron Rad. 15, 632-640 (2008).

49. Newville, M. IFEFFIT: interactive XAFS analysis and FEFF fitting. J. Synchrotron Rad. 8, 322-324 (2001).

50. Ravel, B. \& Newville, M. ATHENA, ARTEMIS, HEPHAESTUS: data analysis for X-ray absorption spectroscopy using IFEFFIT. J. Synchrotron Rad. 12, 537-541 (2005)

\section{Acknowledgements}

We gratefully thank the Smart Mix Program of the Netherlands Ministry of Economic Affairs and the Netherlands Ministry of Education, Culture and Science within the framework of the CatchBio Program. M.S. is grateful to the Research Executive Agency (REA) of the European Commission for awarding a Marie Curie Intra-European Fellowship for Career Development (FP7-PEOPLE-IEF-2010 Grant Agreement No. 275755). C. van de Spek (Utrecht University), Dr J. Gao (Utrecht University) and T.W.G.M. Verhoeven (Eindhoven University of Technology) are acknowledged for the TEM, $\mathrm{N}_{2}$ physisorption and XPS measurements, respectively.

\section{Author contributions}

W.L. performed the catalytic experiments, carried out the FT-IR experiments and analysed the XPS data under the guidance of P.C.A.B. and B.M.W. M.S. prepared all the MIm catalysts, while A.M.B., M.S. and W.L. performed the XAS measurements and A.M.B. analysed the EXAFS data; Q.H. performed the STEM and XEDS measurements under the guidance of C.J.K. All authors contributed to the discussion and manuscript preparation. P.C.A.B. and B.M.W. supervised the project.

\section{Additional information}

Supplementary Information accompanies this paper at http://www.nature.com/ naturecommunications

Competing financial interests: W.L., M.S., P.C.A.B. and B.M.W. declare competing financial interests as the work described in this publication is part of a patent application (PCT/NL2014/050569).

Reprints and permission information is available online at http://npg.nature.com/ reprintsandpermissions/

How to cite this article: Luo, W. et al. High performing and stable supported nano-alloys for the catalytic hydrogenation of levulinic acid to $\gamma$-valerolactone. Nat. Commun. 6:6540 doi: $10.1038 /$ ncomms7540 (2015)

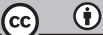

This work is licensed under a Creative Commons Attribution 4.0 International License. The images or other third party material in this article are included in the article's Creative Commons license, unless indicated otherwise in the credit line; if the material is not included under the Creative Commons license, users will need to obtain permission from the license holder to reproduce the material To view a copy of this license, visit http://creativecommons.org/licenses/by/4.0/ 